\title{
Maxillofacial Radiology 174
}

SADJ September 2019, Vol. 74 No. 8 p464

CJ Nortjé

A twelve year old female presented with a bony hard swelling (Fig.1) of the right maxilla of six months duration. The lesion extended from the philtrum to the zygomatic arch, obliterating the nasolabial fold. Intraorally the extension was from the 11 to the 17. There was buccal and palatal expansion and the 15 and 16 were mobile. What is your diagnosis?
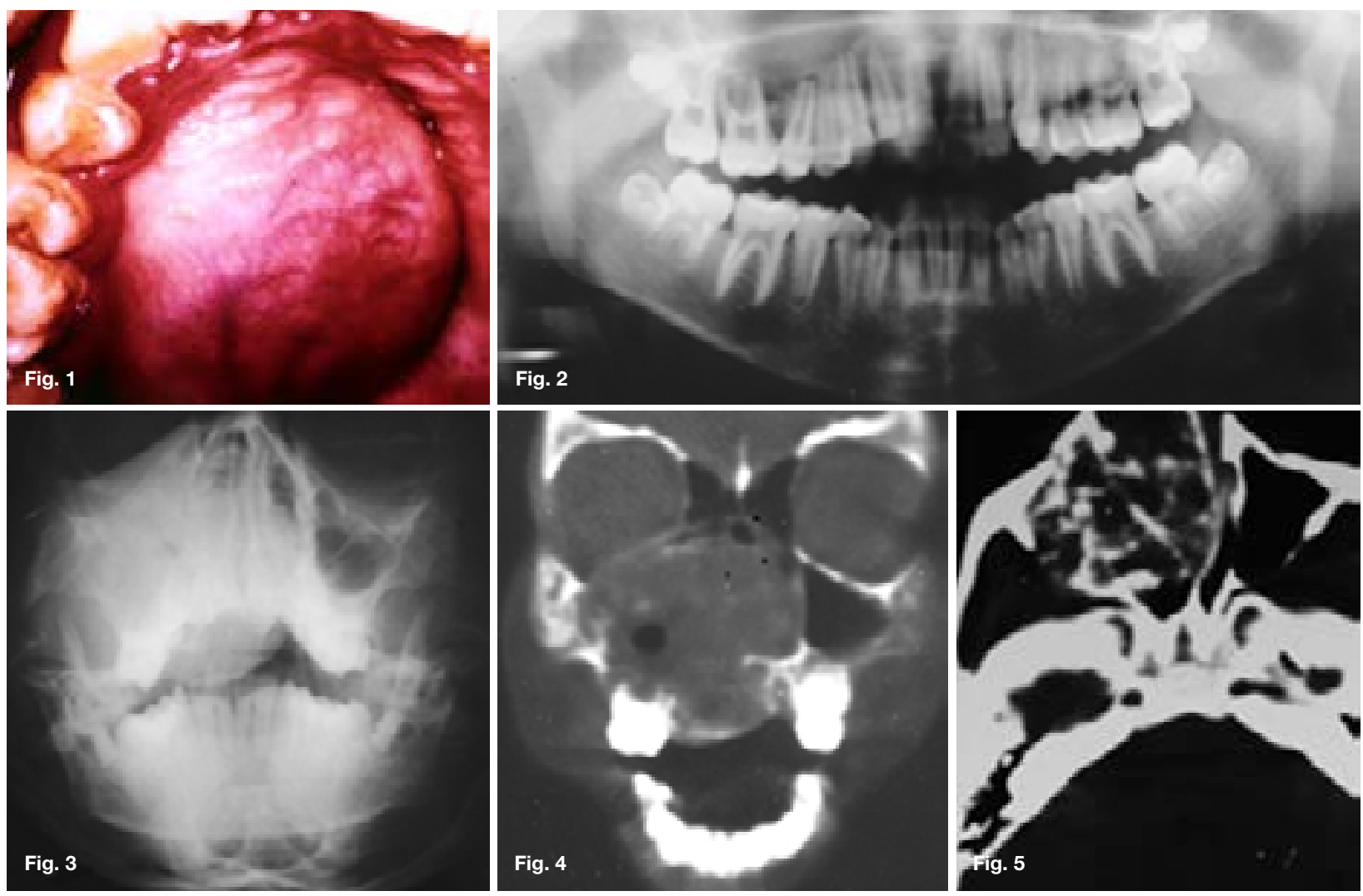

INTERPRETATION

Figure 2 and 3 revealed an ill-defined radiopaque lesion of the right maxilla extending into the maxillary sinus, the nasal cavity, displacing the nasal septum, the infratemporal fossa and inferiorly into the hard palate and oral cavity. The coronal soft tissue window (Fig. 4) shows the lesion extending superiorly into the ethmoid sinus and orbital floor. Non-contrast axial bone window (Fig. 5) shows a large multilocullar expansile lesion within the maxilla. A histological diagnosis of a plasma cell myeloma (Plasmacytoma) was made. This is an unusual lesion which some authorities believe to be unrelated to multiple myeloma even though the two are microscopically indistinguishable. The lesion affects only a single bone. Infrequently, it is seen in soft tissue, in which case, the term extramedullary plamacytoma is used. The criteria for establishing a diagnosis of solitary plasma cell myeloma are not well defined. Multiple myeloma usually runs an invariably fatal course within two years, or at least becomes widely dissemi-

Christoffel J Nortjé: $B C h D, P h D, A B O M R, D S c$. Faculty of Dentistry, University of the Western Cape.

ORCID Number: 0000-0002-9717-5514

Email: cnortje@uwc.ac.za

nated in that period. Christopherson and Miller, in reviewing 51 cases of solitary plasma cell myeloma, found a predilection for the sixth decade, although the age range of the patients was from 19 months to 72 years. Males were affected more frequently than females, as in multiple myeloma. The authors also stated that all cases surviving for three years without evidence of dissemination or "metastasis" may be considered true examples of solitary myeloma. Radiographically, the lesion may be seen as a well-defined, unilocular radiolucency with no evidence of sclerotic borders or as a ragged radiolucency similar to multiple myeloma. There is nothing pathognomic or even characteristic of the roentgenographic features of solitary plamacytoma. Plasmacytoma are usually treated with radiation therapy. Lesions have been surgically excised with good results, although this is not the preferred treatment in most instances. Unfortunately, when patients with plasmacytoma of bone are observed on a long-term basis most will develop multiple myeloma.

\section{Reference}

1. Christopherson, WM; \& Miller, AJ: A re-evaluation of solitary plasma-cell myeloma of bone. Cancer, 3: 240, 1950. 